\title{
Medical costs associated with cardiovascular events among high-risk patients with hyperlipidemia
}

\author{
Machaon M Bonafede' \\ Barbara H Johnson' \\ Akshara Richhariya ${ }^{2}$ \\ Shravanthi R Gandra ${ }^{2}$ \\ 'Outcomes Research, Truven Health \\ Analytics, Cambridge, MA, USA; \\ ${ }^{2}$ Global Health Economics, Amgen, \\ Thousand Oaks, CA, USA
}

\author{
This article was published in the following Dove Press journal: \\ ClinicoEconomics and Outcomes Research \\ 9 June 2015 \\ Number of times this article has been viewed
}

\begin{abstract}
Objectives: This study descriptively examined acute and longer term direct medical costs associated with a major cardiovascular (CV) event among high-risk coronary heart disease risk-equivalent (CHD-RE) patients. It also gives a firsthand look at fatal versus nonfatal CV events.
\end{abstract}

Methods: The MarketScan ${ }^{\circledR}$ Commercial Claims and Encounters Database was used to identify adults with a CV event in 2006-2012 with hyperlipidemia or lipid-lowering therapy use in the 18 months prior to one of the following inpatient CV events: myocardial infarction, ischemic stroke, unstable angina, transient ischemic attack, percutaneous coronary intervention, or coronary artery bypass graft (CABG). Patients were required to have a preindex diagnosis of at least one of the following: peripheral arterial disease, abdominal aortic aneurysm, carotid artery disease, or diabetes. A subset analysis was conducted with patients with data linkable to the Social Security Administration Master Death File. Direct medical costs were reported for each quarter following a CV event, for up to 36 months after the first CV event.

Results: In total, 38,609 CHD-RE patients were included, mean age 57 years, 31\% female. $\mathrm{CABG}$, myocardial infarction, and percutaneous coronary intervention were the most frequent and most expensive first $\mathrm{CV}$ events, accounting for $>75 \%$ of all first $\mathrm{CV}$ events with mean first quarter costs ranging from $\$ 17,454$ (nonfatal transient ischemic attack) to $\$ 125,690$ (fatal CABG). Overall, $15 \%$ of those with a first $\mathrm{CV}$ event went on to have a second event during the 36-month study period with mean first quarter nonfatal and fatal costs similar to first event levels. Third CV events were rare, happening in less than $3 \%$ of patients.

Conclusion: $\mathrm{CV}$ events among CHD-RE patients were costly regardless of sequence, averaging $\$ 47,433$ in the first 90 days following an event and remaining high, never returning to preevent levels. When fatal, first CV event costs were 1.2 to 2.9 times higher than when nonfatal.

Keywords: coronary heart disease risk equivalent, economic burden, subsequent CV event, fatal CV event

\section{Introduction}

Cardiovascular disease (CVD) is the leading cause of death in the US $(32.3 \%$ of deaths in 2009) and accounts for $17 \%$ of national health expenditures. ${ }^{1,2}$ Coronary heart disease (CHD) is one of the main manifestations of CVD. In 2011, there were approximately 26.5 million adults diagnosed with heart disease in the US. ${ }^{3}$ Almost half of adults in the US (47\%) had at least one of the main risk factors for CVD in 2009-2010: uncontrolled high blood pressure, uncontrolled high low-density lipoproteins (LDL) cholesterol, or smoking. ${ }^{4}$ Individuals with clinical CHD, peripheral arterial disease (PAD), abdominal aortic aneurysm (AAA), or diabetes in conjunction with uncontrolled high LDL cholesterol are considered CHD events risk-equivalent (CHD-RE) patients
Correspondence: Machaon M Bonafede Outcomes Research, Truven Health Analytics, 77 Rowell Road, Brentwood, $\mathrm{NH} 03833$, USA

Tel +l 6035805587

Fax +l 6174929365

Email machaon.bonafede@truvenhealth. com 
according to the Adult Treatment Pathways III guidelines. ${ }^{5}$ CHD-RE patients are at increased risk for acute CV events, including myocardial infarction (MI), heart failure, unstable angina (UA), angina pectoris, other ischemic heart disease, ischemic stroke, or transient ischemic attack (TIA). Each year, approximately 620,000 American men and women have their first coronary event (eg, MI), and an additional 295,000 have a recurrent event. ${ }^{5,6}$

Given the high prevalence of risk factors, CVD, and CVD events in the US population, the associated costs are substantial. In 2010, the estimated direct medical costs and indirect costs of CVD were estimated to be $\$ 273$ billion and $\$ 172$ billion, respectively. ${ }^{2}$ By 2030, direct medical costs are predicted to increase multiplicatively to $\$ 818$ billion. $^{2}$ In a recent study of the costs of specific $\mathrm{CV}$ events, mean index hospitalization cost of a CV event (heart failure, MI, $\mathrm{UA}$, angina pectoris, other ischemic heart disease, ischemic stroke, TIAs, and PAD) ranged from $\$ 6,447$ for TIA to $\$ 33,207$ for coronary artery bypass graft (CABG). In the following year, the average total cost across all $\mathrm{CV}$ events was $\$ 16,582$ compared to a mean cost of $\$ 2,790$ for matched controls during the same time period. ${ }^{7}$ In a case-control cost estimation study of CV event, costs attributed to MI (ie, costs for cases with an MI minus costs for controls) in the month of the event were $\$ 34,200$, and at 12 months, the cumulative cost differential was $\$ 55,600{ }^{8}$

The high acute costs of CV events are well established. The economic burden of longer term costs and fatal costs, as well as costs of subsequent events, have not been thoroughly examined among those patients at high risk. The objective of this study was to update the existing literature with more recent cost estimates associated with incident acute $\mathrm{CV}$ events, to fill current gaps by describing the cost of subsequent $\mathrm{CV}$ events, and to describe the costs associated with fatal (versus nonfatal) $\mathrm{CV}$ events among high-risk CHD-RE patients.

\section{Patients and methods Study design}

This was a retrospective cohort analysis of adult commercially insured patients with a diagnosis of hyperlipidemia or use of a lipid-lowering therapy. These high-risk CHD patients were also required to have a preindex diagnosis of PAD, AAA, coronary artery disease (CAD), or diabetes. Patients were classified according to their index (incident) CV event: MI, ischemic stroke (stroke), UA, TIA, CABG, or percutaneous coronary intervention (PCI). Multiple events within the same hospitalization (index or otherwise) were classified according to the following hierarchy: MI, stroke, UA, TIA, heart failure PCI, and CABG. That is, if a patient had both MI and UA in one hospitalization, the CV event was classified as an MI event. If a patient had both MI and $\mathrm{CABG}$, then it was classified as an MI event. Direct medical costs and incremental costs were reported for each quarter following a $\mathrm{CV}$ event, for up to 36 months after the first (or subsequent) $\mathrm{CV}$ event. Incremental costs were calculated using each patient's baseline costs as the comparator using the entire 18-month preindex period to calculate an average cost per day. The baseline cost used in the incremental cost calculation was calculated using the same number of days of follow-up. Stated otherwise, if a patient only had 63 days of follow-up in a reporting quarter, the baseline cost would be calculated as average cost per day multiplied by 63. A subset analysis of fatal versus nonfatal events was conducted.

\section{Data source}

Claims data from the Truven Health Analytics MarketScan ${ }^{\circledR}$ Commercial Claims and Encounters Database and the Mortality Database between January 1, 2006, and December 31, 2012, were utilized for this study. The MarketScan Commercial Claims and Encounters Database contains the annual data of inpatient, outpatient, and outpatient prescription drug experience of several million employees and their dependents, covered under a variety of fee-for-service and managed care health plans, including exclusive provider organizations, preferred provider organizations, point of service plans, indemnity plans, and health maintenance organizations. The MarketScan Mortality Database integrates death information, which is purchased from the Social Security Administration, with the enrollment and claims data for a subset of individuals who are found in the MarketScan Commercial Claims and Encounters population. This subset consists of individuals for whom a death could be ascertained including the month and year of death.

\section{Subject selection}

Nonelderly adult patients aged 18-64 years were required to have a diagnosis of hyperlipidemia or lipid-lowering therapy use in addition to a diagnosis for CAD, PAD, AAA, or diabetes (Adult Treatment Pathways III guidelines definition of CHD-RE) in the 18 months prior to one of the following inpatient CV events: MI, stroke, UA, TIA, or a PCI or $\mathrm{CABG}$ procedure. The entire study period spanned from July 1, 2004, to December 31, 2012, and the index CV event must have occurred between January 1, 2006, and October 1, 2012 , to ensure that patients had a minimum of 3 months of 
follow-up for the assessment of outcomes. A subset analysis was conducted with patients with data linkable to the Social Security Administration Master Death File. Patients with any $\mathrm{CV}$ events (including heart failure) in the18-month preindex period were excluded because the study is designed to evaluate incident $\mathrm{CV}$ events with sufficient baseline data available.

\section{Outcome measures}

The key outcome measures were all-cause quarterly costs (including inpatient, outpatient hospital, emergency room, outpatient office, other outpatient services, and outpatient pharmacy) calculated after each CV event(s) (first, second, and third). Baseline costs were calculated as the all-cause average costs per quarter. Postindex costs were calculated as the total all-cause costs postindex, by quarter. Incremental costs were calculated for each quarter in the postindex as the difference between the total quarterly cost and the patient's quarterly baseline cost. An estimate of first-year costs was calculated by summing the first four quarters of incremental cost. All costs were adjusted to 2013 US\$ using the medical care services component of the Consumer Price Index. ${ }^{9}$

\section{Analysis}

Baseline demographic characteristics, including age, sex, urban versus rural residence, geographic region, and insurance plan type were assessed for each patient. Comorbid burden at baseline was measured by the Deyo-Charlson Comorbidity Index and presence of the following specific conditions: hypertension, dyslipidemia, respiratory disease, renal disease, and arthritis. CV event sequencing was presented as the proportion of patients with second and third events along with the type of event during the 3-year postindex study period. Baseline, postindex, and incremental cost were calculated for each of the 12 quarters following the index event for all first, second, and third events by index CV event type and cohort.

A separate analysis of fatal and nonfatal CV event costs was conducted among the subset of patients with available mortality data. Statistical analysis was performed using generalized linear models with gamma-distributed error and $\log$ link. First CV event costs were adjusted for the following demographic and clinical characteristics measured at index and in the 18-month preindex period, respectively: age, sex, region, urban versus rural residence, insurance plan type, preperiod expenditures, Deyo-Charlson Comorbidity Index, arthritis, cancer, diabetes, dyslipidemia, hypertension, osteoporosis, renal disease, and respiratory disease.

\section{Results}

A total of 38,609 CHD-RE patients met the patient selection criteria, mean age 57.0 years (standard deviation [SD] 6.0) and $31 \%$ female. Most patients (79\%) lived in urban areas in the South (44\%) or North Central (28\%) region of the US, which is reflective of the study data source. The three most commonly held health insurance plans were exclusive or preferred provider organization at $57 \%$, health maintenance organization at $16 \%$, and point of service at $11 \%$ (Table 1 ).

Table I Demographic and clinical characteristics of CHD-RE patients

\begin{tabular}{|c|c|c|}
\hline \multirow{3}{*}{$\begin{array}{l}\text { Demographic } \\
\text { characteristics }\end{array}$} & \multicolumn{2}{|l|}{ CHD-RE } \\
\hline & \multicolumn{2}{|l|}{$N=38,609$} \\
\hline & N/mean & $\% / S D$ \\
\hline Age (mean, SD) & 57.0 & 6.0 \\
\hline \multicolumn{3}{|l|}{ Age cohort (N, \%) } \\
\hline $18-34$ & 140 & $0.4 \%$ \\
\hline $35-44$ & $|, 5| \mid$ & $3.9 \%$ \\
\hline $45-54$ & 9,285 & $24.0 \%$ \\
\hline $55-64$ & 27,673 & $71.7 \%$ \\
\hline Male (N, \%) & 26,659 & $69.0 \%$ \\
\hline Urban (N, \%) & 30,654 & $79.4 \%$ \\
\hline \multicolumn{3}{|l|}{ Geographic region (N, \%) } \\
\hline North East & 5,644 & $14.6 \%$ \\
\hline North Central & 10,867 & $28.1 \%$ \\
\hline South & 16,895 & $43.8 \%$ \\
\hline West & 4,907 & $12.7 \%$ \\
\hline Unknown & 296 & $0.8 \%$ \\
\hline \multicolumn{3}{|l|}{ Insurance plan type (N, \%) } \\
\hline Comprehensive/indemnity & 2,805 & $7.3 \%$ \\
\hline EPO/PPO & 22,236 & $57.6 \%$ \\
\hline POS/POS w/capitation & 4,065 & $10.5 \%$ \\
\hline $\mathrm{HMO}$ & 6,181 & $16.0 \%$ \\
\hline CDHP/HDHP & 1,370 & $3.5 \%$ \\
\hline Missing/unknown & 1,952 & $5.1 \%$ \\
\hline \multicolumn{3}{|l|}{ Risk cohort criteria (N, \%) } \\
\hline Diabetes & 32,549 & $84.3 \%$ \\
\hline Peripheral arterial disease & 6,715 & $17.4 \%$ \\
\hline Coronary artery disease & 5,124 & $13.3 \%$ \\
\hline Abdominal aortic aneurysm & 954 & $2.5 \%$ \\
\hline Deyo-Charlson comorbidity & 2.0 & 1.6 \\
\hline \multicolumn{3}{|l|}{ index (mean, SD) } \\
\hline \multicolumn{3}{|l|}{ Comorbid conditions (N, \%) } \\
\hline Hypertension & 25,911 & $67.1 \%$ \\
\hline Dyslipidemia & 22,900 & $59.3 \%$ \\
\hline Respiratory disease & 17,507 & $45.3 \%$ \\
\hline Renal disease & 6,344 & $16.4 \%$ \\
\hline Arthritis (OA/RA) & 6,483 & $16.8 \%$ \\
\hline Statin use (N, \%) & 34,569 & $89.5 \%$ \\
\hline
\end{tabular}

Note: Risk cohort criteria are not mutually exclusive; therefore, proportions will total $>100 \%$.

Abbreviations: CHD-RE, coronary heart disease risk equivalent; SD, standard deviation; HMO, health maintenance organization; POS, point of service; PPO, preferred provider organization; EPO, exclusive provider organization; CDHP, consumer-driven health plan; HDHP, high deductible health plan; OA, osteoarthritis RA, rheumatoid arthritis. 
Diabetes was the most prevalent risk-equivalent diagnosis among the CHD-RE patients (84\%), while AAA was the least prevalent $(2.5 \%)$. Less than one in five had PAD (17\%) or CAD (13\%). The overall mean Deyo-Charlson Comorbidity Index was 2.0 (SD 1.6). Two-thirds of patients had baseline hypertension, $59 \%$ had baseline dyslipidemia, and $45 \%$ had baseline respiratory disease. Approximately $17 \%$ of patients had evidence of arthritis and another $16 \%$ had evidence of renal disease in the 18 months prior to their first $\mathrm{CV}$ event. Overall, $90 \%$ of the study sample had evidence of baseline statin use (Table 1).

The most common first CV event was PCI (31\%) followed by MI (26\%), CABG (20\%), stroke (14\%), TIA (7\%), and UA (2\%) (Figure 1). The four most frequently occurring first $\mathrm{CV}$ events were also the most expensive. Mean first quarter (Q1) nonfatal direct costs were $\$ 77,701$ (SD 55,845) for CABG followed by $\$ 47,869$ (SD 53,193) for MI and were very similar for PCI and stroke $(\$ 38,744$ [SD 37,936] and $\$ 37,323$ [SD 47,711], respectively). First event UA and TIA mean Q1 nonfatal direct costs were lowest at $\$ 23,361$ (SD 34,270) and $\$ 17,454$ (SD 17,928), respectively.

Overall, $15 \%$ of those with a first CV event went on to have a second event during the 36-month study period (Table 2). The proportion of patients with a second CV event

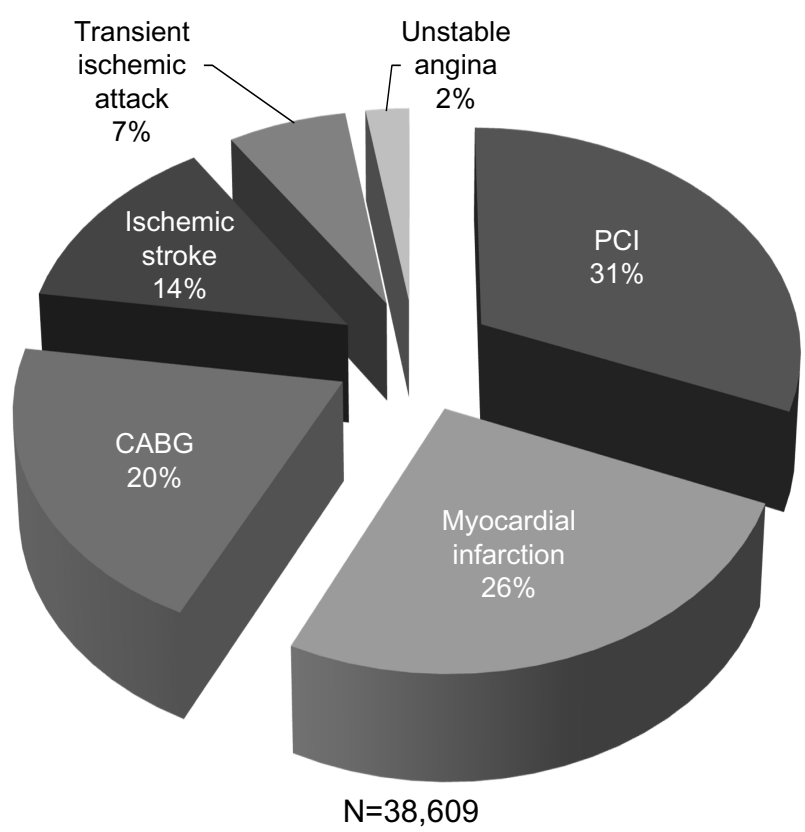

Figure I Patient proportions of index cardiovascular event.

Notes: Multiple events within the same index hospitalization were classified according to the following hierarchy, which was created to take into account the principal reason for the hospitalization: myocardial infarction, stroke, unstable angina, transient ischemic attack, percutaneous coronary intervention, and coronary artery bypass graft.

Abbreviations: $\mathrm{CABG}$, coronary artery bypass graft; $\mathrm{PCl}$, percutaneous coronary intervention.
Table 2 Subsequent CV events among CHD-RE patients

\begin{tabular}{lll}
\hline Subsequent CV event & \multicolumn{2}{l}{ CHD-RE } \\
\cline { 2 - 3 } & \multicolumn{2}{l}{$\mathbf{N = 3 8 , 6 0 9}$} \\
\cline { 2 - 3 } & Number & $\%$ \\
\hline Presence of second CV event (N, \%) & 5,782 & $15.0 \%$ \\
Type of second CV event (N, \%) & & \\
MI & 1,596 & $4.1 \%$ \\
Stroke & 796 & $2.1 \%$ \\
Unstable angina & 72 & $0.2 \%$ \\
TIA & 277 & $0.7 \%$ \\
Heart failure & 17 & $0.0 \%$ \\
Revascularization (CABG and PCl) & 3,024 & $7.8 \%$ \\
Presence of third CV event (N, \%) & 1,078 & $2.8 \%$ \\
Type of third CV event (N, \%) & & \\
MI & 267 & $0.7 \%$ \\
Stroke & 159 & $0.4 \%$ \\
Unstable angina & 19 & $0.0 \%$ \\
TIA & 64 & $0.2 \%$ \\
Heart failure & 2 & $0.0 \%$ \\
Revascularization (CABG and PCl) & 567 & $1.5 \%$ \\
\hline
\end{tabular}

Abbreviations: $\mathrm{CV}$, cardiovascular; CHD-RE, coronary heart disease risk equivalent; MI, myocardial infarction; TIA, transient ischemic attack; CABG, coronary artery bypass graft; $\mathrm{PCl}$, percutaneous coronary intervention.

differed by index CV event. Second CV events were seen most frequently among patients with a first event MI or UA (21\%) and less frequently for those whose first event was TIA $(10 \%)$. The proportion of patients with first event stroke and revascularization (CABG and $\mathrm{PCI}$ ) who had a second event was closer to the mean at $15 \%$ and $12 \%$, respectively. The type of second CV event also differed by index CV event, but for the majority, were the same type as the first. For example, of the patients whose index CV event was MI and had a second $\mathrm{CV}$ event, $>50 \%$ had a second $\mathrm{MI}$, whereas of the patients whose index CV event was stroke and who had a second CV event, two-thirds had a second stroke. Third CV events were uncommon, happening in less than $3 \%$ of patients (Figure 2). Despite these differences, for the majority of $\mathrm{CV}$ events, the sequence of the event had little bearing on the overall cost. The only notable exception was $\mathrm{CABG}$, where the cost increased considerably as a second and third event compared to cost as a first event. Among those with a second or third event, the proportion of those with heart failure was extremely rare $(0.3 \%$ as a second event and $0.2 \%$ as a third event); therefore, the cost fluctuation is not unexpected (Figure 3 and Table 3).

Estimated 1-year mean direct costs were greatest for $\mathrm{CABG}$ as the first $\mathrm{CV}$ event (without a subsequent $\mathrm{CV}$ event) at $\$ 79,253$, followed by $\mathrm{MI}$ at $\$ 52,485$, stroke at $\$ 44,007$, and PCI at $\$ 41,146$. UA and TIA estimated costs were considerably lower at $\$ 21,956$ and $\$ 18,672$, respectively (data not shown). 


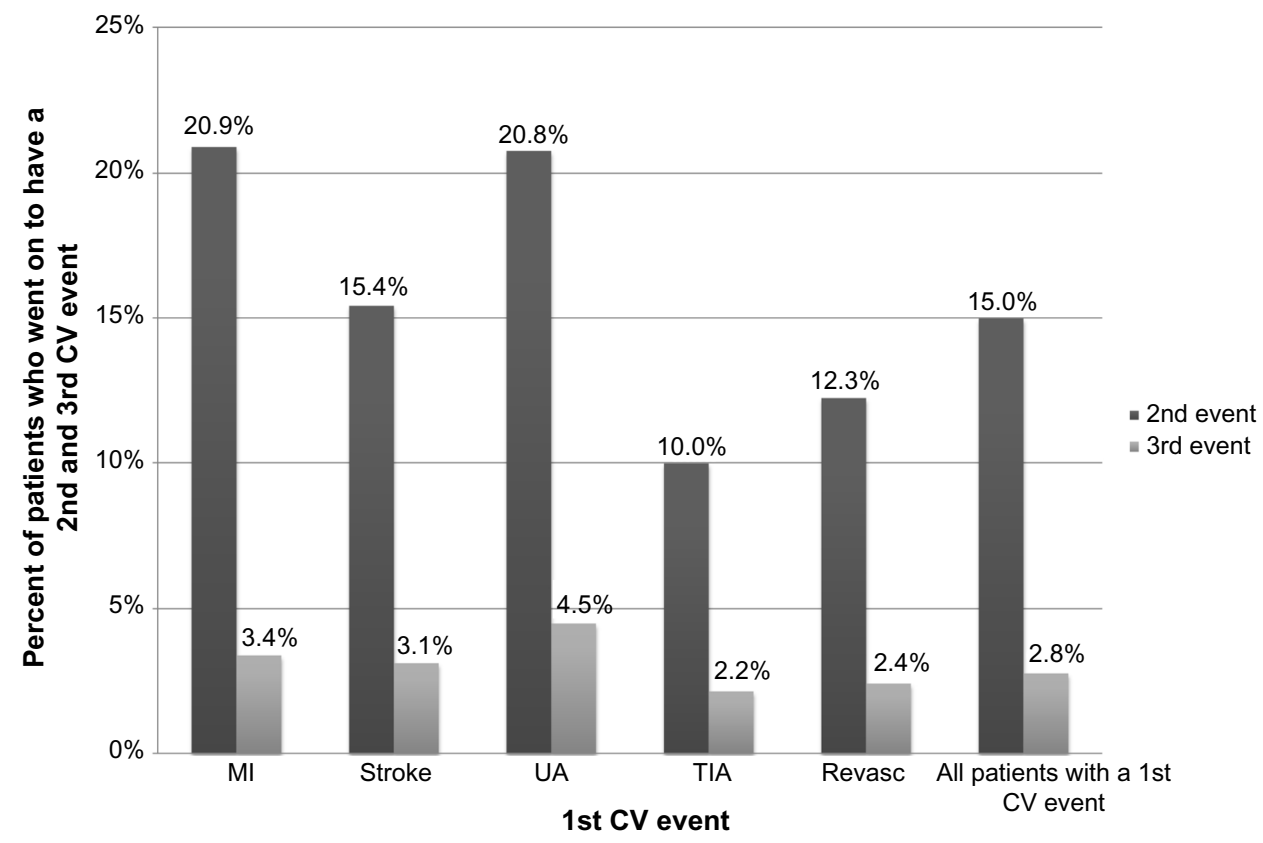

Figure 2 Proportion of patients with second and third CV events stratified by first CV event.

Notes: Revascularization includes both coronary artery bypass graft and percutaneous coronary intervention.

Abbreviations: CV, cardiovascular; MI, myocardial infarction; UA, unstable angina; TIA, transient ischemic attack; Revasc, revascularization.

For all first $\mathrm{CV}$ events, mean direct costs were highest in the acute timeframe, dropped in the Q2, and most essentially flattened by the Q3 but remained consistently higher than baseline for the entire 36-month follow-up period. TIA and UA were exceptions to the rule. Mean quarterly direct costs for
TIA were found to be similar to the majority until the middle of the second year (Q7), when costs started a rise-and-fall pattern, which lasted throughout the end of the third year (Q12). Mean quarterly direct costs for UA never settled, rising and falling and actually peaking at the end of the third year to a level

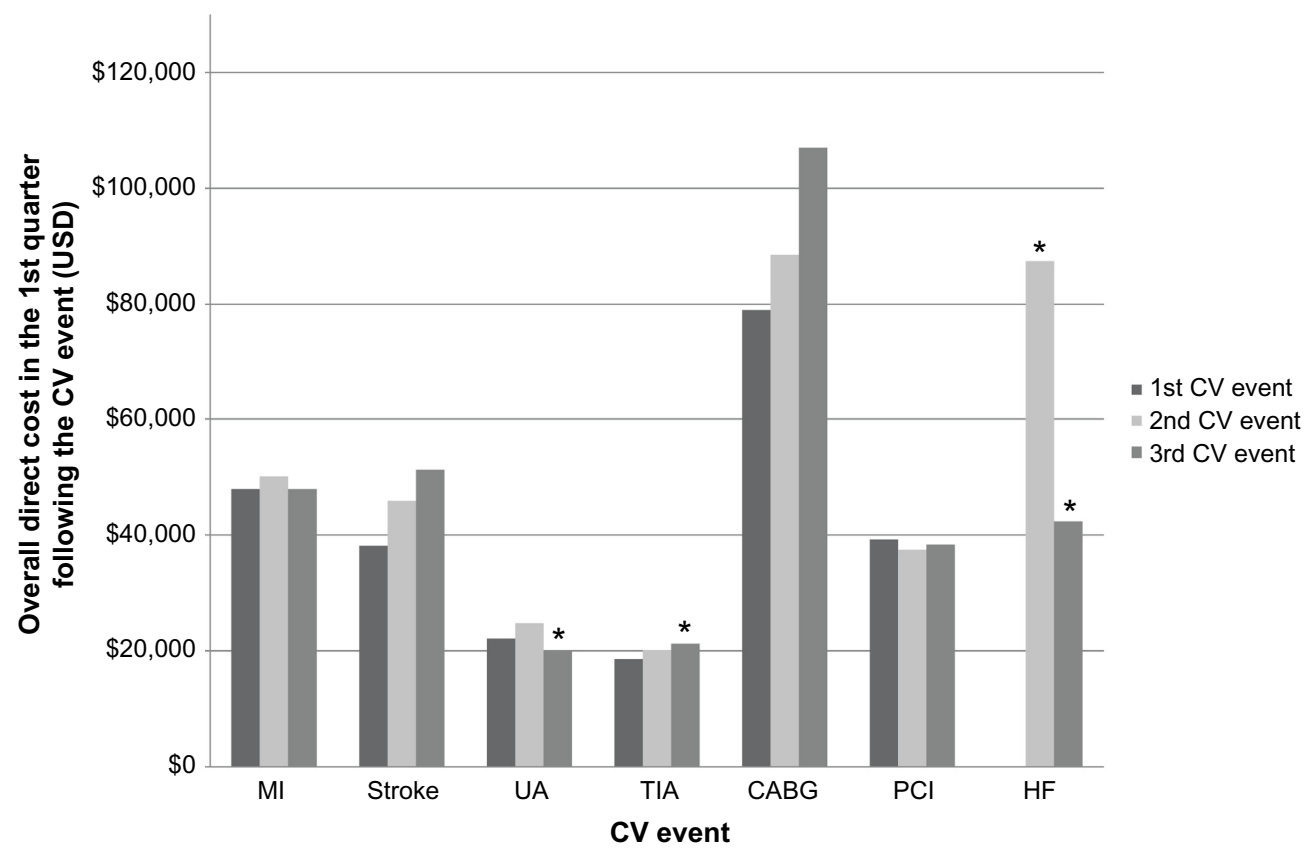

Figure 3 First quarter costs by CV event as a first, second, or third event.

Notes: *indicates a sample size of $<50$. Heart failure could only be a second or third event among the study population; therefore, costs for heart failure as a first event are not included in the figure.

Abbreviations: CV, cardiovascular; $\mathrm{MI}$, myocardial infarction; UA, unstable angina; TIA, transient ischemic attack; CABG, coronary artery bypass graft; PCl, percutaneous coronary intervention; HF, heart failure. 
Table 3 Frequency and acute incremental costs of first, second, and third CV events

\begin{tabular}{|c|c|}
\hline \multirow[t]{2}{*}{ First CV event } & \multirow{2}{*}{$\begin{array}{l}\text { CHD-RE } \\
\mathrm{N}=38,609\end{array}$} \\
\hline & \\
\hline Myocardial infarction $(\mathrm{n}, \%)$ & $9,963,25.8 \%$ \\
\hline Incremental postindex cost (mean, SD) & $\$ 44,808, \$ 48,122$ \\
\hline Stroke $(\mathrm{n}, \%)$ & $5,218,13.5 \%$ \\
\hline Incremental postindex cost (mean, SD) & $\$ 34,158, \$ 48,759$ \\
\hline Unstable angina $(\mathrm{n}, \%)$ & $959,2.5 \%$ \\
\hline Incremental postindex cost (mean, SD) & $\$ 18,902, \$ 32,628$ \\
\hline Transient ischemic attack (n, \%) & $2,602,6.7 \%$ \\
\hline Incremental postindex cost (mean, SD) & $\$ 13,982, \$ 22,489$ \\
\hline CABG $(n, \%)$ & $7,875,20.4 \%$ \\
\hline Incremental postindex cost (mean, SD) & $\$ 74,562, \$ 55,642$ \\
\hline $\mathrm{PCl}(\mathrm{n}, \%)$ & $12,125,31.4 \%$ \\
\hline Incremental postindex cost (mean, SD) & $\$ 35,323, \$ 34,658$ \\
\hline Second CV event & $\mathrm{N}=5,782$ \\
\hline Myocardial infarction $(\mathrm{n}, \%)$ & $1,596,4.1 \%$ \\
\hline Incremental postindex cost (mean, SD) & $\$ 46,484, \$ 61,032$ \\
\hline Stroke $(n, \%)$ & $796,2.1 \%$ \\
\hline Incremental postindex cost (mean, SD) & $\$ 42,050, \$ 57,587$ \\
\hline Unstable angina $(n, \%)$ & $72,0.2 \%$ \\
\hline Incremental postindex cost (mean, SD) & $\$ 18,808, \$ 30,323$ \\
\hline Transient ischemic attack (n, \%) & $277,0.7 \%$ \\
\hline Incremental postindex cost (mean, SD) & $\$ 14,602, \$ 22,046$ \\
\hline Heart failure $(n, \%)$ & $17,0.0 \%$ \\
\hline Incremental postindex cost (mean, SD) & $\$ 83,198, \$ 65,544$ \\
\hline CABG $(n, \%)$ & $707,1.8 \%$ \\
\hline Incremental postindex cost (mean, SD) & $\$ 84,971, \$ 68,37$ I \\
\hline $\mathrm{PCl}(\mathrm{n}, \%)$ & $2,334,6.0 \%$ \\
\hline Incremental postindex cost (mean, SD) & $\$ 33,844, \$ 38,57 \mid$ \\
\hline Third CV event & $N=I, 078$ \\
\hline Myocardial infarction (n, \%) & $267,0.7 \%$ \\
\hline Incremental postindex cost (mean, SD) & $\$ 43,525, \$ 61,945$ \\
\hline Stroke $(n, \%)$ & $159,0.4 \%$ \\
\hline Incremental postindex cost (mean, SD) & $\$ 47,309, \$ 75,098$ \\
\hline Unstable angina (n, \%) & $19,0.0 \%$ \\
\hline Incremental postindex cost (mean, SD) & $\$ 15,900, \$ 18,499$ \\
\hline Transient ischemic attack (n, \%) & $64,0.2 \%$ \\
\hline Incremental postindex cost (mean, SD) & $\$ 17,285, \$ 23,120$ \\
\hline Heart failure $(n, \%)$ & $2,0.0 \%$ \\
\hline Incremental postindex cost (mean, SD) & $\$ 40,438, \$ 1,155$ \\
\hline CABG (n, \%) & $123,0.3 \%$ \\
\hline Incremental postindex cost (mean, SD) & $\$ 102,907, \$ 107,390$ \\
\hline $\mathrm{PCl}(\mathrm{n}, \%)$ & $444,1.1 \%$ \\
\hline Incremental postindex cost (mean, SD) & $\$ 34,341, \$ 34,078$ \\
\hline
\end{tabular}

Notes: Incremental acute costs were calculated as the difference between the first quarter total postindex cost and the patient's quarterly baseline cost. All currency is USD.

Abbreviations: CV, cardiovascular; CHD-RE, coronary heart disease risk equivalent; SD, standard deviation; CABG, coronary artery bypass graft; $\mathrm{PCl}$, percutaneous coronary intervention.

slightly higher than the initial Q2 drop level. It is important to note that common among all first $\mathrm{CV}$ events, mean quarterly direct costs never went back to pre-CV event levels during the 36 months after the first CV event (Figure 4).

Over two-fifths of the study sample ( $\mathrm{n}=16,321)$ had mortality data available. Fatal CV events, though uncommon in this study population ( $<2 \%$ as a first event, $2 \%$ and $3 \%$ as second and third events, respectively), were much more costly than nonfatal-like $\mathrm{CV}$ events and there was considerable variation by type of fatal event. Patients with first event stroke and MI were more likely to have a fatal event than those with UA, TIA, or a revascularization ( $4 \%, 3 \%$, and $1 \%$, respectively). The adjusted costs of a fatal MI event were 1.2 times that of a nonfatal MI first event, whereas costs of a fatal first event UA were 2.9 times that of a nonfatal UA. Costs attributed to $\mathrm{CABG}$ and PCI as a fatal event were 1.6 and 1.7 times that of a nonfatal first event, respectively (Table 4).

\section{Discussion}

To our knowledge, this is the first study to describe fatal costs of commercially insured nonelderly, high-risk CHD-RE patients. Additionally, this study contributes to the existing literature with more recent acute $\mathrm{CV}$ event and subsequent $\mathrm{CV}$ event costs and an update on longer term cost estimates. The current study found that the costs of $\mathrm{CV}$ events were similar within each event type (MI, stroke, UA, heart failure, TIA) regardless of the event sequence. For example, as a first, second or third event, acute MI costs ranged from $\$ 43,525$ to $\$ 46,484$, suggesting that the type of event is a stronger driver of event costs than the number or sequence of $\mathrm{CV}$ events. Fatal first $\mathrm{CV}$ events were associated with significantly higher costs than nonfatal first $\mathrm{CV}$ events, ranging from 1.2 to 2.9 times higher (approximately $\$ 9,000-\$ 53,000$ ) depending on the event type.

CABG was common in this sample, potentially making it a significant driver of total $\mathrm{CV}$ event costs. Reynolds et al, in a cost and outcomes study of revascularization procedures, reported that $4.5 \%$ had a repeat CABG, $4 \%$ had an MI after revascularization, and $3 \%$ of patients died within a 3 -year follow-up period. ${ }^{10}$ These results were comparable to the present study, where $4.2 \%$ of patients had a repeat CABG procedure and $2 \%$ had an $\mathrm{MI}$ in the 3-year follow-up period. Mortality results for the 3 years following a CABG procedure in the current study were lower than the 3-year results reported by Reynolds et al, with only $1 \%$ of patients dying following a $\mathrm{CABG}$ revascularization procedure.

Overall, mortality rates following an acute $\mathrm{CV}$ event ranged from $1 \%$ to $4 \%$ in the 3 months following the acute event. The proportion of CHD-RE patients who died in the Q1 was 3\% for those with an MI index event and 1\% for those with an UA index event. This is in alignment with previous estimates of $\mathrm{CV}$ event mortality. Etemad and McCollam, in a cost study of acute coronary syndrome (ACS) in a managed care population, reported that $3.6 \%$ of patients died during the 1-year follow-up 


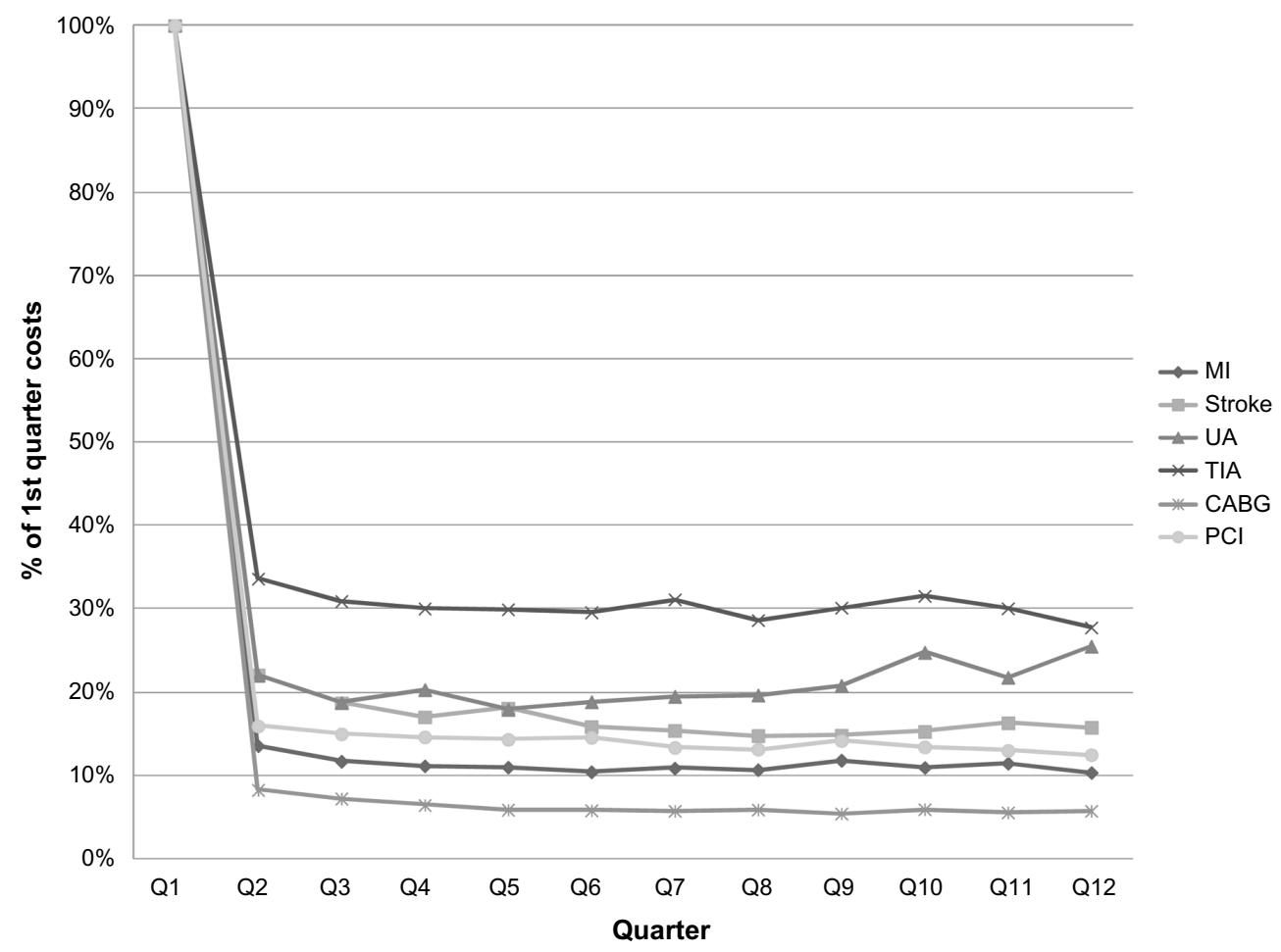

Figure 4 Quarterly CV event costs through year three as a proportion of first quarter costs by index CV event.

Abbreviations: CV, cardiovascular; MI, myocardial infarction; UA, unstable angina; TIA, transient ischemic attack; CABG, coronary artery bypass graft; PCI, percutaneous coronary intervention; QI, first quarter; Q2, second quarter; Q3, third quarter; Q4, fourth quarter; Q5, fifth quarter; Q6, sixth quarter; Q7, seventh quarter; Q8, eighth quarter; Q9, ninth quarter; Q10, tenth quarter; QII, eleventh quarter; Q12, twelfth quarter.

period. ${ }^{11}$ ACS patients are comparable to those with MI or UA in the present study. An earlier study of ACS patients reported similar mortality findings; $2.3 \%$ of UA patients and $5.6 \%$ of MI patients died within 1 month of the event. ${ }^{12}$

Although $18 \%$ of patients in this population had a subsequent event and the presence of second or third events was more common among patients with MI, UA, or stroke as a first event, overall, the proportion of patients with subsequent events was lower than previously reported. In a cost study of ischemic stroke patients from January 2002 through December 2003, Engel-Nitz et al reported that over a third of patients had a subsequent hospitalization and the majority of those were for recurrent stroke and/or TIA. ${ }^{13}$ This proportion of patients with subsequent stroke and/or TIA was significantly higher than the proportion found in the current study where only $18.5 \%$ of patients with an index stroke event had a subsequent $\mathrm{CV}$ event. The drop in the proportion of patients with subsequent events and the lower $\mathrm{CABG}$ mortality rates in the current study could be further evidence that better treatment (both pharmacological and interventional) is improving mortality and outcomes in this high-risk patient group. ${ }^{14}$

Despite improving mortality and outcome trends, index hospitalization costs for acute and subsequent events remain high and are higher than medical costs reported in some earlier studies. For example, in their study of administrative claims from a large US managed care plan, Engel-Nitz et al reported index hospitalization costs for stroke patients, which were significantly less than comparable costs in the current study $(\$ 15,634$ vs $\$ 34,158) .{ }^{13}$ In part, this may be due to general health care cost inflation over the past 10 years, but it also may be indicative of the higher cost to treat these high-risk patients. Consistent with the findings using administrative claims data from both Chapman et al and O'Sullivan et al, CV event costs varied widely between $\mathrm{CV}$ event types. ${ }^{7,8}$ As expected, and as is consistent with other published studies, acute $\mathrm{CV}$ event costs are significantly higher among CHD-RE patients than among those patients not meeting this criteria. ${ }^{7,8}$

One-year cost estimates were comparable to the literature. For example, Ward et al, in a recent study of the cost of complications among diabetes patients assessed from the perspective of a comprehensive US health care payer, reported 1 -year mean direct medical costs for MI $(\$ 56,445)$ and stroke $(\$ 42,119) .{ }^{15}$ Their reported 1 -year costs (based on a combination of actual and estimated costs) were very similar to the incremental 1-year costs for first MI $(\$ 52,485)$ and stroke 


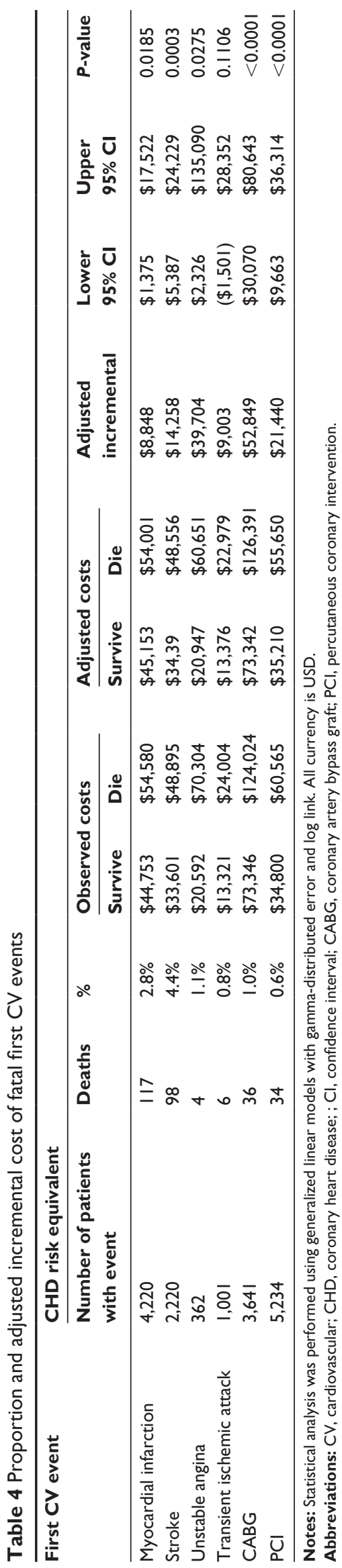

$(\$ 44,007)$ events among CHD-RE patients. Although not all patients in the CHD-RE cohort had diabetes, $84 \%$ of patients were diagnosed with diabetes prior to their index $\mathrm{CV}$ event, so this group has clinical characteristics similar to the patients examined by Ward et al. In study of ACS patients in the Medicare population, mean costs in the first year following the event were $\$ 50,458$, which are also comparable to the first-year costs for CHD-RE patients following MI $(\$ 52,485)$ in this commercially insured population. ${ }^{16}$

The limitations of this study include those inherent in any retrospective analysis. First, this study was limited to nonelderly individuals with commercial health coverage. Consequently, results of this analysis may not be generalizable to patients with Medicare, other insurance, or without health insurance. Second, the potential for misclassification of risk cohorts, covariates, or study outcomes is present as patients were identified through administrative claims data as opposed to medical records. As with any claims databases, the MarketScan Research Databases rely on administrative claims data for clinical detail. These data are subject to data coding limitations and data entry error. Third, study design dictated that patients had to have either a diagnosis of hyperlipidemia or statin use in the baseline; therefore, the intensity of statin therapy at $90 \%$ is not comparable to other claims-based studies that did not require baseline statin use or population-based statin use, which is estimated at $48.1 \% .{ }^{17}$ Fourth, because the associated laboratory data were not available for the full study cohort, this study is not able to ascertain how successful statin treatment was at getting LDL to goals. Fifth, the ability to distinguish event types was limited to International Classification of Diseases, Ninth Revision, Clinical Modification coding, which was used for event type assignment. Sixth, patients were followed for a maximum of 36 months after their first CV event; therefore, the analysis does not capture subsequent $\mathrm{CV}$ events or associated costs beyond 36 months. Finally, costs in this study were limited to direct medical costs only. Indirect costs, due to absenteeism and short- and long-term disability leave, are likely to be high in this population.

\section{Conclusion}

While advances in pharmacological and interventional treatments have reduced CV event risk, economic burden of CVD among high-risk patients is substantial, both in the acute phase as well as over the longer term, with baseline costs never returning to pre-CV event levels. Though uncommon, fatal CV events have substantially higher costs than nonfatal events. Future research in this important area should focus on treatments that may further reduce LDL cholesterol in high- 
risk patients and decrease the incidence and costs associated with CV events.

\section{Acknowledgment}

This work was funded by Amgen Inc.

\section{Disclosure}

MMB and BHJ are employees of Truven Health Analytics, which received financial support from Amgen Inc. to conduct the analyses. AR and SRG are employees and stockholders of Amgen Inc. The authors report no other conflicts of interest in this work.

\section{References}

1. Go AS, Mozaffarian D, Roger VL, et al. Heart disease and stroke statistics - 2013 update: a report from the American Heart Association. Circulation. 2013;127(1):e6-e245.

2. Heidenreich PA, Trogdon JG, Khavjou OA, et al; American Heart Association Advocacy Coordinating Committee; Stroke Council, Council on Cardiovascular Radiology and Intervention; Council on Clinical Cardiology; Council on Epidemiology and Prevention; Council on Arteriosclerosis; Thrombosis and Vascular Biology; Council on Cardiopulmonary; Critical Care; Perioperative and Resuscitation; Council on Cardiovascular Nursing; Council on the Kidney in Cardiovascular Disease; Council on Cardiovascular Surgery and Anesthesia; Interdisciplinary Council on Quality of Care and Outcomes Research. Forecasting the future of cardiovascular disease in the United States: a policy statement from the American Heart Association. Circulation. 2011;123(8):933-944.

3. Schiller JS, Lucas JW, Peregoy JA. Summary health statistics for US adults: National Health Interview Survey, 2011. Vital Health Stat 10. 2012;256:1-207.

4. Fryar CD, Chen TC, Li X. Prevalence of uncontrolled risk factors for cardiovascular disease: United States, 1999-2010. NCHS Data Brief. 2012;103:1-8.

5. NIH. ATP III Guidelines At-A-Glance Quick Desk Reference National. NIH Publication 01-3305; 2001.
6. Go AS, Mozaffarian D, Roger VL, et al. Heart disease and stroke statistics - 2014 update: a report from the American Heart Association. Circulation. 2014;129(3):e28-e292.

7. Chapman RH, Liu LZ, Girase PG, Straka RJ. Determining initial and follow-up costs of cardiovascular events in a US managed care population. BMC Cardiovasc Disord. 2011;11:11.

8. O'Sullivan AK, Rubin J, Nyambose J, Kuznik A, Cohen DJ, Thompson D. Cost estimation of cardiovascular disease events in the US. Pharmacoeconomics. 2011;29(8):693-704.

9. United States Department of Labor Bureau of Labor Statistics. Consumer Price Index for All Urban Consumers (CPI-U): US city average, by expenditure category. Econ News Release. 2013; USDL14-0037:10. Available from: http://www.bls.gov/news.release/archives/ cpi_01162014.pdf.

10. Reynolds MR, Neil N, Ho KK, et al. Clinical and economic outcomes of multivessel coronary stenting compared with bypass surgery: a single-center US experience. Am Heart J. 2003;145(2):334-342.

11. Etemad LR, McCollam PL. Total first-year costs of acute coronary syndrome in a managed care setting. J Manag Care Pharm. 2005;11(4): 300-306.

12. Eisenstein EL, Shaw LK, Anstrom KJ, et al. Assessing the clinical and economic burden of coronary artery disease: 1986-1998. Med Care. 2001;39(8):824-835.

13. Engel-Nitz NM, Sander SD, Harley C, Rey GG, Shah H. Costs and outcomes of noncardioembolic ischemic stroke in a managed care population. Vasc Health Risk Manag. 2010;6:905-913.

14. Zhao Z, Winget M. Economic burden of illness of acute coronary syndromes: medical and productivity costs. BMC Health Serv Res. 2011;11:35.

15. Ward A, Alvarez P, Vo L, Martin S. Direct medical costs of complications of diabetes in the United States: estimates for event-year and annual state costs (USD 2012). J Med Econ. 2014;17(3):176-183.

16. Chen SY, Crivera C, Stokes M, Boulanger L, Schein J. Clinical and economic outcomes among hospitalized patients with acute coronary syndrome: an analysis of a national representative Medicare population. Clinicoecon Outcomes Res. 2013;5:181-188.

17. Centers for Disease Control and Prevention (CDC). Vital signs: prevalence, treatment, and control of high levels of low-density lipoprotein cholesterol - United States, 1999-2002 and 2005-2008. MMWR Morb Mortal Wkly Rep. 2011;60(4):109-114.
ClinicoEconomics and Outcomes Research

\section{Publish your work in this journal}

ClinicoEconomics \& Outcomes Research is an international, peerreviewed open-access journal focusing on Health Technology Assessment, Pharmacoeconomics and Outcomes Research in the areas of diagnosis, medical devices, and clinical, surgical and pharmacological intervention. The economic impact of health policy and health systems

\section{Dovepress}

organization also constitute important areas of coverage. The manuscript management system is completely online and includes a very quick and fair peer-review system, which is all easy to use. Visit http://www.dovepress.com/testimonials.php to read real quotes from published authors. 